\title{
Avaliação de desempenho da Agência Nacional de Vigilância Sanitária no modelo de contrato de gestão
}

\author{
The Brazilian National Health Surveillance Agency \\ performance evaluation at the management contract model
}

Elka M altez de $\mathrm{M}$ iranda M oreira ${ }^{1}$

Ediná Alves Costa ${ }^{2}$

${ }^{1}$ Diretoria de Vigilância SanitáriaeAmbiental, Secretaria de Saúde do Estado da Bahia. Centro de Atenção a SaúdeProf. Dr. José $M$ aria de $M$ agalhães Netto. Av. Antônio Carlos $M$ agalhães $\mathrm{s} / \mathrm{n}$, I guatemi. 41820-000 Salvador BA. elkamaltez@yahoo.com.br ${ }^{2}$ Centro Colaborador em Vigilância Sanitária, Instituto deSaúdeColetiva UniversidadeFederal da Bahia.
Abstract The Brazilian National Health Surveillance Agency (Anvisa) is supervised by the Ministry of $\mathrm{H}$ ealth by means of a management contract, a performance evaluation tool. This case study was aimed at describing and analyzing Anvisa's performance evaluation model based on the agency's institutional purpose, according to the following analytical categories: the management contract formalization, evaluation tools, evaluators and institutional performance. Semi-structured interviews and document analysis revealed that Anvisa signed only one management contract with the M inistry of $\mathrm{H}$ ealth in 1999 , updated by four additive terms. The Collegiate Board of Directorsand the Advisory Center for Strategic $M$ anagement play the role of Anvisa's internal evaluators and an Assessing Committee, comprising the $M$ inistry of $\mathrm{H}$ ealth, constitutes its external evaluator. Three phases were identified in the evaluation model: the structuring of the new management model (1999-2000), legitimation regarding the productive segment (2001-2004) and widespread legitimation (2005). The best performance was presented in 2000 (86.05\%) and the worst in 2004 (40.00\%). The evaluation model was shown to have contributed little towards the agency's institutional purpose and the effectiveness measurement of the implemented actions.

Key words Management contract, Performance evaluation, Sanitary surveillance, Anvisa
Resumo A Agência Nacional de Vigilância Sanitária (Anvisa) é acompanhada pelo M inistério da Saúdemediantecontrato degestão, instrumento de avaliação de desempenho. Realizou-se estudo de caso mediante entrevistas semiestruturadas com atores selecionados e análise documental, objetivando descrever eanalisar o modelo de avaliação de desempenho da Anvisa, com vistas à finalidade da instituição, de acordo com as seguintes categorias analíticas: formalização do contrato de gestão, instrumentos de avaliação, sujeito avaliador e desempenho institucional. As entrevistas semiestruturadas e a análise documental indicam que a Anvisa celebrou um contrato de gestão, em 1999, atualizado por quatro termos aditivos. 0 avaliador interno é representado pela Diretoria Colegiada e N úcleo de Assessoramento à Gestão Estratégica; 0 avaliador externo, por uma Comissão de Avaliação constituída pelo M inisté rio da Saúde. Identificaram-setrêsfases do modeIo avaliativo: estruturação do novo model o de gestão (1999-2000), legitimação ante o segmento produtivo (2001-2004) e ampliação da legitimação (2005). 0 melhor desempenho ocorreu em 2000 ( $86,05 \%)$, e o pior em 2004 (40,00\%). Verificou-se que o modelo de avaliação pouco avançou em direção à finalidade institucional e aferição da efetividade das ações realizadas. Pal avras-chave Contrato degestão, Avaliação de desempenho, Vigilância sanitária, Anvisa 
Introdução

Vigilância sanitária pode ser concebida como subárea da Saúde Coletiva e campo singular de articulações complexas entre o domínio econômico, o jurídico-político e o médico-sanitário ${ }^{1}$, englobando atividades de natureza interdisciplinar, multiprofissional e interinstitucional. Suas ações preventivas e de caráter regulatório perpassam todas as práticas médico-sanitárias e demandam conhecimentos de diversas áreas do saber que se intercomplementam de forma articulada².

Asfunções de vigilância sanitária (Visa) envolvem o controle de riscos de variados objetos, tanto aqueles que respondem a necessidades sociais em saúde e constituem "meios de vida" quanto outros, inventados pelo mercado para necessidadesartificialmente criadas ${ }^{3}$. Taisfunções são compartilhadas com os diferentes níveis de gestão do Sistema N acional de V igilância Sanitária (SNVS) - componente do Sistema Ú nico de Saúde(SUS) - eoutros setores institucionais, como Agricultura e Pecuária, M eio Ambiente e Trabal ho.

A Agência Nacional de Vigilância Sanitária (Anvisa), primeira agência reguladora na área social do país, éresponsável pela execução deum conjunto de atribuições no âmbito federal e coordenação do SNVS. Surgiu em 1999, no contexto da reforma gerencial do Estado brasileiro, cuja política foi expressa no Plano Diretor da Reforma do Aparelho do Estado 4 . Este plano buscava a evolução do modelo burocrático de administração, focado em padrões hierárquicos rígidos e no controle de processos, para um modelo de administração gerencial, baseado na eficiência, controle deresultadose atendimento com qualidade ao cidadão ${ }^{5}$.

A agência reguladora deveria substituir a estrutura burocrática e ultrapassada da Secretaria ministerial de Vigilância Sanitária, combater os graves e históricos problemas sanitários nacionais relacionados a produtos e serviços e forne cer respostas mais ágeis ao mercado globalizado. 0 novo modelo organizacional, caracterizado pela independência administrativa, estabilidade de dirigentes e autonomia financeira, concederia maior autonomia para a realização de ações e estabel eceria o acompanhamento ea avaliação do seu desempenho pelo M inistério da Saúde (M S), através de um contrato de gestão ${ }^{6}$.

0 modelo deavaliação de desempenho baseado no contrato de gestão não éuma novidade da reforma do Estado brasileiro. A experiência internacional recente demonstra que a avaliação dedesempenho esteve frequentementeassociada à utilização de formas contratuais ou semicontratuais entre os órgãos da administração pública e as entidades ou órgãos responsáveis pela implementação de políticas públicas ou prestação de serviços públicos?

O contrato de gestão tem sua origem teórica na "administração por objetivos", caracterizada pela eleição de áreas prioritárias numa organização, estabelecimento de resultados a serem alcançados, dimensionamento de metas e acompanhamento sistemático do desempenho ${ }^{5}$. Foi idealizado no direito francês como meio de controle administrativo ou tutela sobre as empresas estatais; mas, antes disso, já era utilizado como meio de vincular a programas governamentais determinadas empresas privadas que recebiam do Estado algum tipo de auxílio ${ }^{8}$.

O Brasil se espelhou no modelo francês para implantar seus contratos de gestão. 0 primeiro foi em 1983, com a Rede Ferroviária Federal; entre 1983 e 1990 foram formalizados "Convênios de Desempenho" com oito empresas estatais, entreelasaCompanhiaValedo Rio D oceeaCompanhia Siderúrgica Nacional. Em 1991, foi firmado contrato de gestão entre a União e a Associação das Pioneiras Sociais. Entre 1992 e 1994, o governo federal emitiu dois decretos estabelecendo as condições para celebrar contratos de gestão com a Companhia Vale do Rio Doce e a Petrobras 5,7 .

0 modelo de avaliação de desempenho da Anvisa baseado no contrato de gestão é o objeto deste estudo. Considerou-se o novo arranjo político-organizacional num componente do sistema público desaúde, comprometido, simultaneamente, com o papel regulador (associado ao atributo eficiência) ecom a finalidadede "promover a proteção da saúde da população" (vinculada à redução de riscos, efetividade eimpacto).

Acompanhou-se a trajetória da Agência buscando demonstrar os rumos esentidos do contrato de gestão, com o objetivo de "descrever e analisar o modelo de avaliação de desempenho da Anvisa, tendo em vista a finalidade institucional". 0 pressuposto é que a avaliação de desempenho da Agência esteve fundamentada no atributo eficiência, afastando-se da finalidade da instituição.

\section{M etodologia}

Foi realizado estudo de caso descritivo, apoiado em técnicas de análise documental e de entrevistas semiestruturadas com informantes-chave. 0 local do estudo foi a Anvisa e o período foi delimitado desde sua criação, em 1999, até 2005. 
A estrutura organizacional da Anvisa é composta de Diretoria Colegiada (Dicol) - um dire tor-presidente e quatro diretores -, Procuradoria, Corregedoria, Ouvidoria, Conselho Consultivo, gerências-gerais, gerências enúcleos querepartem as diversas competências.

A identidadeorganizacional, expressa na missão "proteger e promover a saúde da população garantindo a segurança sanitária de produtos e serviços e participando da construção de seu acesso", coaduna-se com o marco legal da saúde/vigilância sanitária (Seção Saúde da Constituição Federal de 1988, Lei no 8.080, de 1990, e Lei $n^{\circ}$ 9.782, de 1999) e a finalidade institucional.

Inicialmente, foram selecionadas e analisadas as fontes documentais, identificando-se lacunas que poderiam ser preenchidas com as entrevistas. Tais fontes foram classificadas em "internas à Anvisa" ( contrato de gestão, termos aditivos, relatórios de execução do contrato de gestão, atas de reuniões do Conselho Consultivo e da Dicol) e "externas à Anvisa" (relatórios da Comissão deAvaliação e parecer da Secretaria de Vigilância em Saúde/MS).

As entrevistas foram realizadas em agosto de 2006, com seisinformantes queexerciam funções na Anvisa, no período de 1999 a 2005: dois dirigentes e quatro representantes do então Núcleo de Assessoramento à Gestão Estratégica (Naest). Os entrevistados foram selecionados de modo a que todo o período de estudo fosse representado e, também, por terem atribuições relacionadas ao contrato de gestão. As entrevistas foram conduzidas na própria sede da instituição com aqueles que exerciam cargo em 2006 ou nos locais de trabalho, com aqueles que já não ocupavam cargo na Anvisa, mediante prévia assinatura de Termo deConsentimento Livree Esclarecido.

O material empírico foi processado e codificado de acordo com as seguintes categorias analíticas:

- Formalização do contrato de gestão da Anvisa - momento da assinatura do instrumento contratual.

- Instrumentos de avaliação - recursos empre gados para avaliar o desempenho institucional.

. Sujeito avaliador - instâncias e atores com atribuições de avaliar o contrato de gestão a partir da posição que ocupam, internamente ou externamente à Anvisa.

- Desempenho institucional - desempenho orçamentário-financeiro e grau de cumprimento das metas estabelecidas.

Os documentos foram categorizados com auxílio de matrizes construídas no softwareWord, versão 2000. As entrevistas foram categorizadas a partir do software QSR N Vivo, versão 2.0, que permitiu a emissão de relatórios e a construção de matrizes em Word.

A categorização de unidades de análise e a reapresentação do material em matrizes permitiram identificar convergências e divergências entre os depoimentos dos entrevistados e os trechos extraídos dos documentos. 0 estudo foi submetido ao Comitê de Ética do Instituto de Saúde Coletiva da Universidade Federal da Bahia.

\section{A formalização do contrato degestão}

A Anvisa formalizou relação contratual com 0 MS em agosto de 1999, tendo por objetivo fomentar e executar atividades deV isa e promover a proteção da saúde da população ${ }^{9}$. 0 clima, na época, era de profunda desconfiança, visto queo modelo de agência reguladora recebia críticas de segmentos sociais que identificavam nele uma forma de recentralização - portanto, retrocesso no processo de construção do SNVS, segundo a diretriz de descentralização do SUS.

A elaboração do contrato de gestão não foi um processo democrático; restringiu-se à alta cúpula do M S eà Dicol, tendo como atores principais o ministro da Saúde na época e o então diretor-presidente da Anvisa, querecebeu os cré ditos dessa elaboração. As fal as seguintes reproduzem impressões de um entrevistado acerca do momento:

Vocêpoderia perguntar: por quenão sefez uma consulta pública? Porque também nós tínhamos um pouco demedo do queestávamos fazendo, porque também a Agência estava sob crivo da maneira como ela foi criada. H ojevocêolha para a Agência enota um certo consenso, mas a Agência foi de certa forma também impingida à sociedade brasileira.

Aí tinha esse clima contra a A gência por parte da inteligência sanitária. Então, não era fácil sair por aí de cara aberta e falar venham cá, companheiros, vamos discutir esse contrato de gestão aqui! Venham dizer o que vocês querem pôr (Entrevistado 1).

A elaboração do instrumento contratual ocorreu ao tempo que esforços eram centrados na estruturação da Anvisa, tarefa considerada pela Dicol mais importante e urgente. H ouve fatores limitantes como tempo exíguo, falta de acúmulo teórico sobre avaliação em Visa e carência de sistemas de informação fundamentados na epidemiologia que permitissem construir indicadores 
de resultado para aferir efetividade ou impacto, como releva o seguinte depoimento:

Nós estamos pensando em coisa muito mais importante, que é estruturar... M as precisa pensar 0 contrato de gestão. $\mathrm{E}$ aí 0 contrato de gestão foi exclusivamente feito em cima de indicadores de estrutura porque nós não tínhamos densidade de discussão para chegar no que poderia ser um contrato de gestão que pensasse em impacto, que pensasse em resultado, e nem tinha um sistema de vigilância epidemiológica que pudesse dar qualquer tipo de resposta sobre as ações de vigi lância sanitária. Então ele foi feito em cima de indicadores de estrutura porque não existia acúmulo! N ão existia reflexão! Então foi uma coisa feita com um certo grau de improviso e com o que estava à mão! (Entrevistado 1).

0 contrato de gestão, em sua origem, era formado por um grande plano de metas de estruturação, elaborado no âmbito da Dicol. A vigência do contrato foi prorrogada através de termos aditivos, sem mudanças substanciais de conteúdo. 0 termo aditivo atualiza 0 contrato de gestão quanto ao plano de metas e montante de recursos financeiros para um dado período. Houve quatro repactuações: em setembro de 2000, janeiro de 2002, setembro de2002 edezembro de $2004^{10}$.

$\mathrm{Na}$ elaboração do 1o termo aditivo, o plano de metas foi revisado, voltando-se para os processos de trabalho da Anvisa. 0 2o e o 3o termos aditivos foram assinados na transição entre os governos Fernando Henrique Cardoso e Lula. São reedições do primeiro, sem que modificações substanciais fossem feitas, já que a mudança de governo não deveria afetar o modelo de agência reguladora preconizado. 0 quarto termo aditivo trouxe mudanças substanciais ao modelo de avaliação, pois considerou os macroprocessos institucionais eos critérios de excelência do Prêmio Nacional da Qualidade.

\section{As fases do modelo avaliativo}

A apreciação dos instrumentos de avaliação de nota que o modelo avaliativo evoluiu em trêsfases: "estruturação do novo modelo de gestão" (1999-2000) " "legitimação ante o segmento produtivo" (2001-2004) e "ampliação da legitimação" (2005).

A fase "estruturação do novo modelo de gestão" compreende o período entre a assinatura do contrato de gestão ea publicação do primeiro termo aditivo, em setembro de 2000. Caracterizou-se pela incipiente formulação de indicadores e cons- trução de elevado número demetas, sem priorização de nenhuma delas mas com predomínio daquelas voltadas à estruturação organizacional.

Em sua gênese, o contrato de gestão era formado por uma agenda de macroações de estruturação típica do nível estratégico que a produziu, a Dicol. O relatório do exercício 1999 demonstra que o primeiro plano de metas continha desde as mais simples, como "elaborar regimentos internos, regulamentos, normas e manuais das diversas áreas, em quatro meses", até metas ambiciosas ou inatingíveis, como "desenvolver sistemas de informação operacionais, gerenciais e nacionais de vigilância sanitária e implantar laboratórios deanálisede produtos, em um ano"11.

Além de metas de estruturação, o plano incluía metas orientadas para as atividades-fins da Anvisa, como "fiscalizar produtos e serviços, reduzir o tempo de concessão de registros de produtos e autorizações de funcionamento de empresas"11. A inclusão de metas finalísticas reflete preocupação dos dirigentes em agregar eficiência, adquirir legitimidade ante o segmento produtivo e recuperar a credibilidade da área que historicamente foi alvo de escândalos, obedecendo à racionalidade da administração gerencial, ilustrada na fala do entrevistado:

Então, era estruturar uma instituição que não permitisse acontecer o que vinha acontecendo de gravidade pela falta da ação da vigilância sanitária. E, acima de tudo, também, uma descrença do setor regulado com relação: - Ah, dou entrada na vigilância sanitária federal, sei lá quando é que vou receber o retorno dessemeu registro, desse meu produto?!

Dizem que essa primeira geração do contrato foi montada muito no âmbito da discussão de gestão mesmo, do que seria a Reforma do A parelho do Estado, do que seria o foco na medida de eficiência da ação (Entrevistado 5).

Computou-se um total acumulado de 82 metas nos relatórios desta fase, cerca de 75 tipos diferentes. Observou-sepredomínio de 22 metas voltadas à "estruturação da instituição", seguidas de vinte metas de "fiscalização e inspeção", 13 de "ações desconcentradas", dez de "diretrizes de funcionamento", seis de "capacitação de Recursos Humanos", três de "evolução institucional" e uma de "articulação institucional".

0 propósito de estruturar o novo modelo de gestão determinou a utilização de métodos de estruturação institucional, com destaque para indicadores e metas de estruturação e produção dos serviços. Nesta fase existiu uma aproximação do modelo ao atributo eficiência. 
A fase "legitimação ante o segmento produtivo" teve início após a publicação do 1 o termo aditivo, em setembro de 2000, e foi até a publicação do 40 termo aditivo, em dezembro de 2004. Caracterizou-se pela redução do número de metas.

Segundo o relatório anual de execução do contrato de gestão exercício 2000, o plano de metas foi revisado na elaboração do 10 termo aditivo, voltando-se para os processos de trabaIho da Anvisa ${ }^{11}$. 0 20 e 0 3은 termos aditivos foram assinados no período de transição entre os governos Fernando Henrique Cardoso e Lula, sem haver modificações substanciais, pois a mudança de governo não deveria afetar o modelo de agência adotado.

Os indicadores e metas desse período foram construídos e classificados a partir da adaptação dos critérios do Balanced Scorecard, metodologia de avaliação de desempenho do âmbito empresarial. D o total acumulado de 87 metas, computaram-se 32 tipos diferentes, predominando 18 de "satisfação dos clientes diretos", seguidos por seis de "desenvolvimento institucional", quatro de "fortalecimento do SNVS", dois de "reconhecimento pela comunidade" e dois de "gestão financeira e de custos" 11 .

Asmetas mais numerosas se referem aos prazos para respostas aos pedidos de registro de produtos; convergem com os depoimentos acerca desse período e corroboram a ideia de que se buscava reduzir os prazos para atender às demandas do segmento produtivo:

Havia uma preocupação tratada obsessivamente dentro da Anvisa de que os processos não podiam ser tão demorados. E que a Anvisa perdia em governabilidade sobre os seus objetos, na medida em que acumulava dívida em relação ao setor regulado, porque não cumpria com aquilo que a própria lei define (Entrevistado 2).

Indicadores e metas constantes nos relatórios desta fase seguiram uma ordem de prioridade, destacando-se os de "satisfação dos clientes dire tos". D eacordo com o relatório do exercício 2001, tal prioridadefoi estabelecida pela Dicol “levando em consideração as políticas do Ministério da Saúde e o impacto de cada meta na missão institucional daAgência" ${ }^{\prime 1}$. No entanto, o caráter quantitativo das metas, em especial daquelas consideradas mais prioritárias, favorece o alcance da eficiência e a satisfação do setor produtivo, em detrimento dequalidade do trabal ho, efetividadedas ações e alcance da missão/finalidade institucional, aspectos observados na fala seguinte:

Eu acho que algumas metas podiam ser consideradas não muito importantes. Não muito im- portantes por quê? Porque na verdade eram metas maisquantitativas do quequalitativas. Então quando você diz que vai reduzir o tempo de concessão de uma coisa para outra e o empresário fica feliz, você podeestar fazendo uma redução detempo eganhando eficiência e, ao mesmo tempo, fazendo um trabalho horroroso. Vocêdeixou de fazer algumas coisas que tinham que ser feitas! Ah, então o problema étempo? Eu faço uma inspeção mais curta. Na verdade, a discussão de redução de tempos para as empresas não quer dizer que você está melhorando a qualidadeda vigilância sanitária no país, pode ser justamente o contrário (Entrevistado 3).

0 propósito de adquirir credibilidade junto ao segmento produtivo determinou que a Anvisa se voltasse para a organização dos seus processos detrabal ho eutilização de indicadores e metas de redução de tempo ou prazos para concessão de registros de produtos. N esta fase também houve maior aproximação ao atributo eficiência.

A fase "ampliação da legitimação" iniciou-se com a publicação do 4 o termo aditivo, em dezembro de 2004, o qual continha pequeno número de metas. As falas seguintes demonstram posicionamentos contrastantes entre representantes do $\mathrm{N}$ aest e da Dicol na fase de aprovação do 4 - termo aditivo; o primeiro advogava a favor e o segundo contra a exclusão de metas voltadas para o cumprimento de prazos de resposta ao segmento produtivo:

A gente queria mudar tanto que não queria nem trazer mais a questão dos prazos, da definição de prazos que era tão criticada. Mas a diretoria decidiu que não (Entrevistado 5).

A pesar de todas as críticas, os indicadores originais quanto à tramitação de processos em grande parte criavam uma mobilização interna para revisão dos processos de trabalho e para 0 aumento da eficiência, numa relação muito íntima com construção da legitimidade da Agência, uma vez que uma parte dessa legitimidade dependia de eficiência. Se a Agência, com seu corpo técnico, com a sua estrutura, não conseguisse melhorar os seus tempos, ela tinha cassada a sua legitimidade. Dada em parte aí pelo setor regulado, mas pelo próprio governo também, na medida em que cobrava da A gência, e cobra até hoje, que ela não funcionasse como uma obstrução ao processo produtivo (Entrevistado 2).

$\mathrm{Na}$ construção dos indicadores e metas foram utilizados os critérios preconizados pelo Prêmio N acional da Qualidade, os macroprocessos definidos na Formulação Estratégica da Anvisa e as categorias descritivas da metodologia utilizada pela Rede Integrada de Informações para a 
Saúde ${ }^{11}$. Percebe-se que este processo foi mais cuidadoso, considerando relevância, validade, especificidade, confiabilidade, relação custo-benefício e a disponibilidade dos dados para cálculo dos indicadores. Cada critério de qualidade foi relacionado a um macroprocesso institucional e, após definição do objeto, foi estipulado no mínimo um indicador e respectiva meta para acompanhamento. Esta dinâmica de trabalho conferiu ao processo um caráter mais harmônico e equilibrado.

O relatório do exercício 2005 mostraque, das 14 metas, sete foram classificadas no critério "resultados", "em virtude da prioridade colocada para a avaliação de desempenho dos serviços e dos processos organizacionais" ${ }^{\prime 1}$. Os outros sete critérios - "Iiderança”, "estratégias e planos", "clientes", "sociedade", "informações e conhecimento", "pessoas" e "processos" - ficaram, cada um, com apenas uma meta. A "ampliação da legitimação" se expressa na melhor distribuição de metas entre setor produtivo, cidadãos e SNVS.

Os propósitos de ampliar a credibilidadejunto à sociedade, induzir efortalecer o SNV V econsolidar o papel de coordenadora deste sistema determinaram que a Anvisa se voltasse para mé todos que enfatizavam a qualidadee a excelência. No entanto, o predomínio de indicadores de "re sultado" não permite afirmar que houve aproximação da efetividade ou impacto, pois esses indicadores não mediam o efeito real das ações desenvolvidas na saúde da população.

\section{O sujeito avaliador}

As "instâncias internas" com atribuições regimentais sobre a avaliação do contrato de gestão são a Dicol eo então N úcleo de Assessoramento à Gestão Estratégica (Naest) ${ }^{12}$. A "instância externa” éa Comissão de Avaliação, constituída pelo M S9.

A Dicol elaborou a primeira versão do contrato em 1999 e aprovou os demais instrumentos de avaliação produzidos pelo $\mathrm{N}$ aest, instância interna que, de fato, realizou a avaliação institucional. A Dicol considerava a avaliação periódica do contrato de gestão uma tar efa técnica e, portanto, de responsabilidade do $\mathrm{N}$ aest: 0 suporte intelectual pra existência e manutenção em re lação ao contrato de gestão sempre foi a equipe do $\mathrm{N}$ aest (Entrevistado 2). Caberiaà Dicol apreciar e aprovar os instrumentos previamente elaborados pelo Naest e encaminhá-los ao MS.

$O$ trabalho realizado pelo $N$ aest é percebido pelos seus representantes como um esforço isola- do, sem muita ausculta e comprometimento da Dicol: É uma área técnica quese preocupa com isso, não éuma área de decisão gerencial nem política. É um esforço isolado do Naest, de se preocupar em manter a chama acesa do contrato de gestão (Entrevistado 5). Este depoimento é convergente com o seguinte achado da análise documental: nenhuma das 54 atas das reuniões semanais da Dicol realizadas entre agosto de 2004 e dezembro de 2005 trata de assuntos atinentes ao contrato de gestão.

Observou-se que o processo de acompanhamento e avaliação do desempenho da Anvisa apresentou um elo mais frágil: o M S como órgão supervisor. Este ministério deveria nomear a Comissão de Avaliação para auxiliá-lo no acompanhamento externo, por meio da elaboração de relatórios, pareceres e sugestões sobre o desempenho da Anvisa.

No entanto, a Comissão de Avaliação, como previsto na Portaria $n^{\circ} 174 / 2000$, formalmente composta por representantes dos M inistérios do Planejamento, Orçamento e Gestão e da Saúde (Secretaria Executiva e Secretaria de Políticas de Saúde) ${ }^{13}$, não funcionou. No governo Fernando Henrique, a Comissão trabalhou informalmente e personalizada em poucos atores na Secretaria Executiva, especialmente o subsecretário de Assuntos Administrativos. No governo Lula, a situação não se modificou com a criação da Secretaria deVigilância em Saúde, queseomitiu da tarefa, apesar de receber a atribuição deacompanhar o contrato de gestão da Anvisa ${ }^{14}$ :

No primeiro momento, era a Secretaria Executiva a vinculação com o contrato de gestão da Anvisa. 0 que eu sei é que havia um canal de comunicação muito legal. A partir de 2003, passou a existir regimentalmente essa atribuição na Secretaria de Vigilância em Saúde. E de fato, pra mim, essegoverno não supervisiona absolutamente, nem acompanha o contrato de gestão da Anvisa. Não houve a renovação de portarias, não há uma Comissão, o processo de supervisão do contrato de gestão da Anvisa está abandonado. E aí eu atrelo, sim, ao estabelecimento dessa atribuição à Secretaria de Vigilância em Saúde, que não colocou na agenda de prioridade dela isso. E aí é uma fragilidade também muito grande do próprio M inistério da Saúde (Entrevistado 5).

Tal depoimento é convergente com os achados da análise documental: a Comissão de Avaliação, materializada nos trabalhos da Secretaria Executiva entre os anos de 2000 e 2002, elaborou quatro relatórios detal hados contendo recomendações acerca dos instrumentos de avaliação e como torná-los mais coerentes com a missão da 
Agência. Com a assunção das atividades pela Se cretaria de Vigilância em Saúde, foi emitido ape nas um breve parecer referente ao primeiro se mestre de 2005.

A frágil supervisão seria explicada pela falta deconhecimento técnico sobre o campo da Visa, no MS, e pelo seu desinteressee desuas secretarias em estabelecer um acompanhamento próximo, como ilustra o depoimento:

0 ministério supervisor não faz esse papel. 0 desconhecimento do próprio propósito da contratualização dentro da Secretaria de Vigilância em Saúde pra mim é claro. Acima de tudo, a ausência da expertise da vigilância sanitária dentro da Secretaria de Vigilância em Saúde (Entrevistado 5).

A "inércia" do Ministério da Saúde causaria efeitos colaterais no processo de avaliação de desempenho, como por exemplo o desestímulo do avaliador interno, a distorção dos instrumentos de avaliação, desobediência às estratégias e crité rios definidos e a utilização de metas pouco desafiadoras. A fala seguinte explora as diferentes facetas que podem ser assumidas pelo contrato de gestão, especialmente na "ausência" do ministério supervisor:

Porque nós não fomos capazes de gerar um modelo maduro e eu acho que em grande parte pela insuficiência na interlocução do ministério supervisor. 0 modelo do contrato de gestão pode obedecer a diferentes lógicas. U ma é a lógica da política de saúde. Essa política traz tais diretrizes, tais prioridades que devem ser traduzidas em atividades, projetos etc., eessas coisastêm que ser acompanhadas e avaliadas no desempenho da instituição, porque são prioridades. Isso significaria uma presença forte do M inistério da Saúde, principalmente na definição do funcionamento e das políticas pra vigilância sanitária, o que não aconteceu. Poderia ter um significado quetalvez não definisse tanto a política em si, mas definisse critério de desempenho, pensando em eficiência e efetividade. Esses dois significariam um papel forte de quem acompanha o contrato de gestão. E não havendo, ele acaba sendo um instrumento endógeno. Aí se vive uma tensão entre duas possibilidades, a possibilidade de ter um instrumento de avaliação que tenha o poder discriminatório, tenha a sensibilidade pra perceber as necessidades de correção de rumos da institui ção, ou seja, um instrumento do planejamento; ou de outro lado, um instrumento formal que pode funcionar como argumento para punição da instituição e dos seus dirigentes. Então é melhor que ele seja um instrumento frouxo, com metas fáceis. A gora, as duas coisas são ruins, senão tiver um encadeamento detodo esse conjunto. Q uer dizer, em teseé possível imaginar que o contrato de gestão seja um instrumento de planejamento, mas isso significa existir um modelo de planejamento funcionante, um acompanhamento próximo (Entrevistado 2).

Dessa forma, o contrato de gestão setransformou em um instrumento: "formal", utilizado para cumprir determinações legais, mas esvaziado dos sentidos de planejamento eavaliação; "conveniente", detentor de metas fáceis, para não gerar restrições à Agência ou punição dos diretores por não cumprimento; "endógeno", desalinhado das necessidades da população e das políticas de saúde em geral, e de vigilância sanitária, em particular.

Os achados deste estudo guardam correspondência com o trabalho desenvolvido por Bar$\mathrm{ca}^{5}$ quanto ao avaliador externo. Nota-se também, em outros trabalhos sobre o campo da Visa ${ }^{1,15}$, que o MS tem dado pouca prioridade às ações de proteção e promoção dentro da agenda da saúde.

\section{O desempenho institucional}

A Agência conseguiu, de certo modo, cumprir suas obrigações e executar o programa de trabaIho. As atas de reuniões do Conselho Consultivo revelaram que a Anvisa apresentou os resultados financei ros e desempenho das metas de forma rotineira perante este Conselho. Apesar da previsão legal, não existiu, no entanto, rotina de prestação de contas e apresentação dos instrumentos de avaliação ao Conselho Nacional de Saúde, enfraquecendo a transparência do processo e a possibilidade de o instrumento contratual traduzir a responsabilização institucional sobre as necessidades de saúde da população.

A Tabela 1 mostra o desempenho da Anvisa quanto ao grau de cumprimento de metas nas trêsfases: estruturação (82,93\%), legitimação ante o segmento produtivo (56,32\%) e ampliação da legitimação (64,28\%). 0 melhor desempenho ocorreu em 2000 (86,05\%), e o pior em 2004 (40,00\%). É importante salientar que no cálculo do desempenho todas as metas possuem o mesmo peso (1), embora algumas sejam consideradas prioritárias. N esse cálculo são computadas somente as ações que possuem metas no contrato de gestão, sem incluir diversas ações realizadas ano após ano no controle de produtos, serviços e ambientes, eque ocupam o maior número de páginas dos relatórios de gestão. 


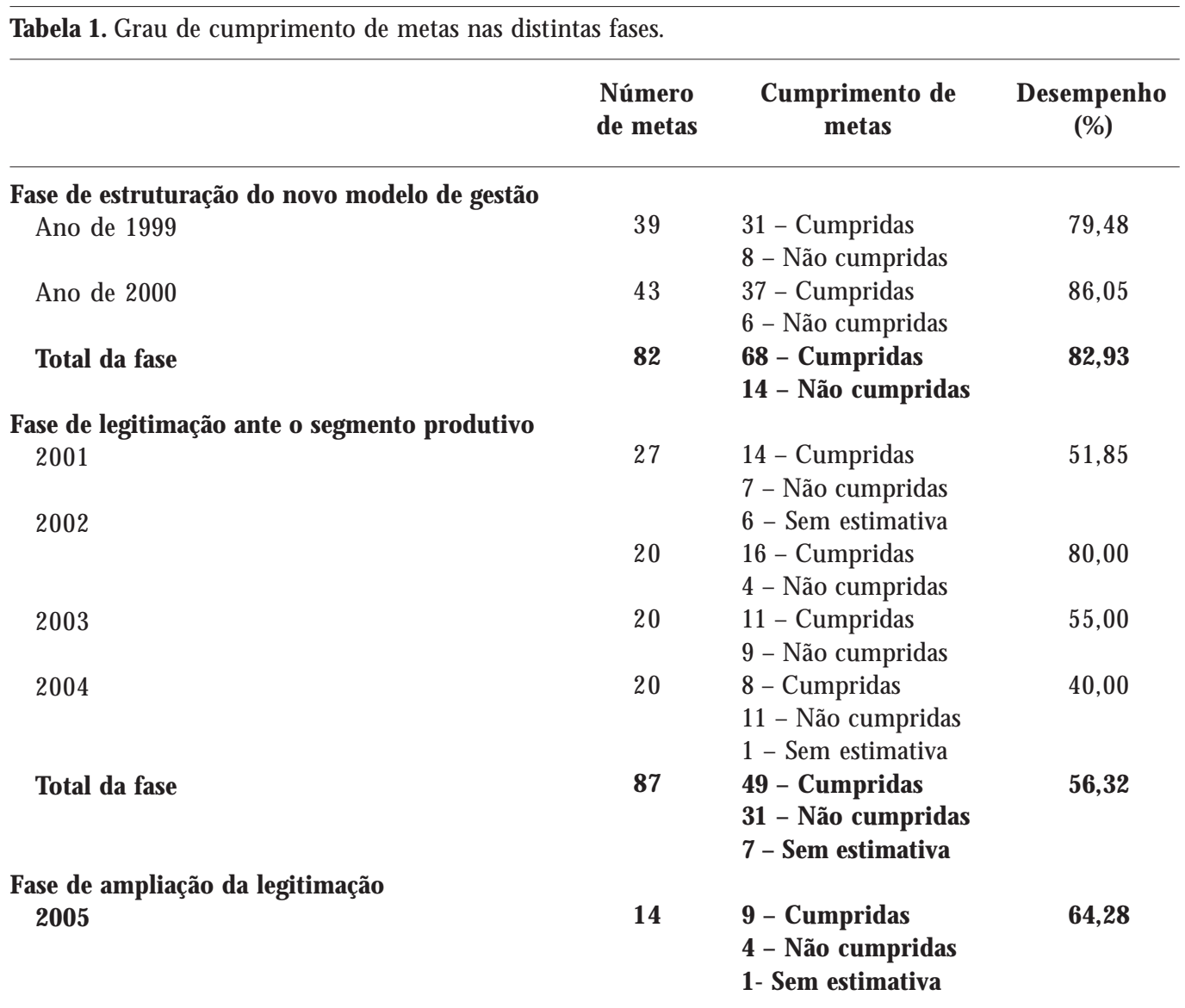

Fonte: Relatórios de Execução do Contrato de Gestão da Anvisa, período 1999-2005.

0 desempenho da organização não melhorou, apesar de crescentes ações e esforços. 0 depoimento a seguir busca explicar essa contradição: o desempenho tem caído, segundo o modelo de avaliação, mesmo com seguidas realizações, porque a dinâmica de avaliação do contrato de gestão está desarticulada da dinâmica de trabalho (planejamento/formulação informal) das diversas gerências da Anvisa:

I númerasaçõesnão são computadas. Então você entende quando eu falo que há uma formulação informal? Porque esta formulação informal retrata exatamente o que a A gência faz, centra esforços e que não está sendo mensurado. Porque na hora que você tem tudo aquilo ali que ela faz, foi dada uma energia pra aquilo ali ser feito, foi dado um empenho, foi decidido politicamente fazer. Então é um instrumento que, de fato, está mensurando 0 desempenho institucional? Não. De que forma a gente deve pensá-lo para dar resposta a isso mesmo? Essa éa questão (Entrevistado 5).
Os relatórios do avaliador externo qualificam como "bom" o desempenho da Anvisa entre 1999 e 2000, "satisfatório" ou "razoável" entre 2001 e 2002 enão avaliam o desempenho a partir de2003.

Quanto ao desempenho orçamentário-financeiro, a Tabela 2 apresenta os recursos autorizados e executados por fonte de financiamento no período 1999-2005 e que demonstram aumento absoluto gradual de recursos provenientes do Tesouro Nacional e da própria Anvisa. Os anos de melhor execução orçamentária foram 2003, 2001 e2004, respectivamente, com 99\% ( $R \$ 208,0$ milhões), $97 \%$ ( $R \$ 172,0$ milhões) e $96 \%$ ( $R \$$ 268,7 milhões) deutilização de recursos.

Em 1999, os recursos autorizados de $R \$ 77,0$ milhões e executados de $\mathrm{R} \$ 74,2$ milhões (96\%) foram atribuídos ao exercício iniciado em setembro daquele mesmo ano. Caso fossem computados os valores de janeiro a dezembro de 1999, correspondendo à soma dos valores de Secretaria de Vigilância Sanitária e Anvisa, a dotação 
autorizada subiria para $\mathrm{R} \$ 140,8$ milhões ea dotação executada para $R \$ 130,5$ milhões, mas 0 percentual de execução cairia para $93 \%$.

0 ano de2005, apesar demaiores valores absolutos ( $R$ \$ 347,6 milhões autorizados e $R$ \$ 328,5 milhões executados), ficou em quinto lugar em termos percentuais ( $95 \%$ de execução), seguido por 2002, em sexto lugar (93\%), e2000, em sétimo lugar (88\%). Os anos de 2003, 2000, 2001 e 1999 foram aqueles que contaram com maior participação da Anvisa em termos percentuais, respectivamente $68 \%$ ( $R$ \$ 141,6 milhões), 65\% ( $R$ \$ 92,4 milhões), $63 \%$ ( $R \$ 108,4$ milhões) e $63 \%$ ( $R$ \$ 46,7 milhões). Os anos de 2002, 2004 e 2005 tiveram menor participação da Anvisa em termos percentuais, com $62 \%$, $57 \%$ e $55 \%$, respectivamente.
A Tabela 3 demonstra a evolução das transferências de recursos fundo a fundo destinadas ao financiamento das ações básicas (PAB) e de mé dia e alta complexidades (M AC) em Visa, executadas pelos estados, municípios e Distrito Federal. Essas transferências são financiadas com recursos da Anvisa e do Fundo N acional de Saúde. Adicionalmente, a Tabela 3 apresenta 0 aumento gradual da arrecadação da Taxa de Fiscalização de Vigilância Sanitária (TFVS) e o resultado patrimonial da Anvisa entreos anos de 1999 e2005.

Os anos de 2003, 2004 e 2005 tiveram os meIhores desempenhos: os valores percentuais de recursos transferidos foram, respectivamente, $44 \%$ ( $R \$ 91,0$ milhões), 37\% ( $R$ \$ 100,3 milhões) e $33 \%$ ( $\$$ \$ 109,9 milhões). Os piores desempe-

Tabela 2. Dotação orçamentária por fonte de financiamento no período 1999-2005 (em R\$1.000.000,00 um milhão de reais).

\begin{tabular}{|c|c|c|c|c|c|c|c|}
\hline \multirow{3}{*}{ Ano } & \multirow{3}{*}{$\begin{array}{c}\text { Autorizado } \\
\text { Total } \\
\mathrm{R} \$\end{array}$} & \multicolumn{6}{|c|}{ Executado } \\
\hline & & \multicolumn{2}{|c|}{ Total } & \multicolumn{2}{|c|}{ Fonte do Tesouro Nacional } & \multicolumn{2}{|c|}{ Fonte da Anvisa } \\
\hline & & $\mathrm{R} \$$ & $\%$ & $\mathrm{R} \$$ & $\%$ & $\mathrm{R} \$$ & $\%$ \\
\hline 1999 & 77,0 & 74,2 & 96 & 27,5 & 37 & 46,7 & 63 \\
\hline 2000 & 161,4 & 141,8 & 88 & 49,4 & 35 & 92,4 & 65 \\
\hline 2001 & 177,6 & 172,0 & 97 & 63,6 & 37 & 108,4 & 63 \\
\hline 2002 & 210,2 & 195,9 & 93 & 73,9 & 38 & 122,0 & 62 \\
\hline 2003 & 209,9 & 208,0 & 99 & 66,4 & 32 & 141,6 & 68 \\
\hline 2004 & 281,2 & 268,7 & 96 & 115,4 & 43 & 153,3 & 57 \\
\hline 2005 & 347,6 & 328,5 & 95 & 147,6 & 45 & 180,9 & 55 \\
\hline
\end{tabular}

Fonte: Relatórios de Execução do Contrato de Gestão da Anvisa, período 1999-2005.

Tabela 3. Evolução da transferência de recursos fundo a fundo, da arrecadação da Taxa de Fiscalização de Vigilância Sanitária (TFVS) e do resultado patrimonial da Anvisa no período 1999-2005 (em R\$ 1.000.000,00 - um milhão de reais).

\begin{tabular}{|c|c|c|c|c|c|}
\hline \multirow[t]{2}{*}{ Ano } & \multirow{2}{*}{$\begin{array}{c}\begin{array}{c}\text { Total } \\
\text { executado }\end{array} \\
\text { R\$ }\end{array}$} & \multicolumn{2}{|c|}{$\begin{array}{l}\text { Transferências fundo } \\
\text { a fundo (PAB e MAC) }\end{array}$} & \multirow{2}{*}{$\begin{array}{c}\begin{array}{c}\text { Arrecadação } \\
\text { da TFVS }\end{array} \\
\text { R\$ }\end{array}$} & \multirow{2}{*}{$\begin{array}{l}\begin{array}{r}\text { Resultado } \\
\text { patrimonial }\end{array} \\
\text { R \$ }\end{array}$} \\
\hline & & $\mathrm{R} \$$ & $\%$ & & \\
\hline 1999 & 74,2 & - & - & 41,0 & - \\
\hline 2000 & 141,8 & 28,3 & 20 & 92,0 & - \\
\hline 2001 & 172,0 & 50,8 & 30 & 101,3 & - \\
\hline 2002 & 195,9 & 53,6 & 27 & 128,9 & - \\
\hline 2003 & 208,0 & 91,0 & 44 & 143,6 & 28,4 \\
\hline 2004 & 268,7 & 100,3 & 37 & 184,0 & 67,9 \\
\hline 2005 & 328,5 & 109,9 & 33 & 187,4 & 96,6 \\
\hline
\end{tabular}

Fonte: Relatórios deExecução do Contrato de Gestão da Anvisa, período 1999-2005. 
nhos foram nos anos de 2001, 2002 e 2000 com, respectivamente, $30 \%$ ( $R \$ 50,8$ milhões), $27 \%$ ( $R \$$ 53,6 milhões) e $20 \%$ ( $R \$ 28,3$ milhões).

A TFVS aumentou em valores absolutos ano a ano, variando de $R \$ 41,0$ milhões em 1999 para $\mathrm{R} \$ 187,4$ milhões em 2005. A TFVS representa a maior fonte de recursos da Anvisa, eseu aumento gradual indica que a Agência apresenta crescente capacidade de adquirir recursos financeiros. Quanto ao resultado patrimonial, só estavam disponíveis os dados de 2003, 2004 e 2005, demonstrando superávits respectivos da ordem de $R \$ 28,4$ milhões, $R \$ 67,9$ milhões e $R \$ 96,6$ milhões.

\section{Considerações finais}

Ainda que este estudo não permita confirmar 0 pressuposto de que a avaliação de desempenho da Anvisa está fundamentada somente no atributo eficiência, considera-se que os meios utilizados priorizaram a eficiência em detrimento da efetividade, atributo mais relacionado à finalidadeinstitucional.

Percebe-se que existiu coerência entrepropósitos e métodos utilizados quando se pensa na função institucional reguladora e suas estratégias de implementação que priorizaram a eficiência na execução dos recursos e no aumento da produtividade. A finalidade de "promover e proteger a saúde da população", afirmada na missão institucional, não apresentou estratégias consistentes de implementação que priorizassem a efetividade das ações realizadas.

Considera-se que a "omissão" da Diretoria Colegiada da Agência, quanto às suas responsabilidades na avaliação do contrato, pode ter contribuído para enfraquecer o instrumento, tornando o processo periférico, formal e burocrático. A supervisão deficientedo M inistério da Saúde parece reiterar o sentimento de "cumprimento burocrático" e limitar a orientação do instrumento contratual no sentido do benefício da sociedadebrasileira.

Considera-se, também, que o contrato de gestão e suas repactuações carecem de mai or legitimidade antea sociedade, pois não foram sub- metidos ao Conselho Nacional de Saúde, tampouco possuem instrumentos normativos que versem sobre o controle social e a sistemática de acompanhamento e avaliação.

Verificou-se que a primeira versão do plano demetas continha macroações "ambiciosas", tanto em número quanto em factibilidade, tal como sonhos da Dicol para estruturar o novo modelo da agência reguladora. Com o passar do tempo, foram-se agregando pautas técnicas, consideradas mais "no terreno do possível", focalizandose nos processos de trabalho e na construção de metas para dar respostas mais rápidas ao segmento produtivo eadquirir credibilidadee legitimação junto a ele. $M$ ais recentemente, a Anvisa buscou ampliar a legitimidade, no referencial da excelência e qualidade, distribuindo metas entre segmento produtivo, Sistema Nacional de Vigilância Sanitária e cidadãos.

A reformulação do modelo avaliativo em 2005, a partir da adoção dos critérios da qualidade, não favoreceu o desempenho institucional quanto ao grau de cumprimento de metas, mantido aquém do esperado, apesar de crescentes realizações da Anvisa. M as em termos financeiros, a Agência demonstrou relevante capacidadedeadquirir recursos, expressa no aumento da arrecadação ano após ano.

0 estudo enfrentou algumas limitações: pequeno número de entrevistas, todas realizadas com atores internos, e fontes documentais também predominantemente internas. Isto pode ter conferido uma perspectiva mais centrada no âmbito da própria Agência. A estratégia de priorizar a visão da Anvisa e não do Ministério da Saúde deveu-seà limitação do tempo acadêmico para análise mais ampliada, o que se recomenda.

Por fim, considera-se que o modelo de avaliação de desempenho da Anvisa deve ser revisto, pois as responsabilidades institucionais na "promoção e proteção da saúde da população" e coordenação do SN V S exigem estratégias quecombinem os elementos típicos da regulação, como eficiência, expertise, transparência e foco em resultados, com elementos relacionados à sua finalidade, tais como efetividade, articulação entre os componentes desse sistema, responsabilização e controle social. 


\section{Colaboradores}

EM M M oreira realizou o estudo e a redação do artigo; EA Costa participou da redação.

\section{Agradecimentos}

Asautoras agradecem aos entrevistados eà Agência $\mathrm{N}$ acional de Vigilância Sanitária pelo apoio e financiamento através do Centro Colaborador em Vigilância Sanitária do Instituto de Saúde Coletiva da Universidade Federal da Bahia.

\section{Referências}

1. Costa EA. Vigilância sanitária: proteção e defesa da saúde. 2ª ed. São Paulo: Sobravime; 2004.

2. Costa EA, Souto AC. Formação de recursos humanos para a vigilância sanitária. Divulgação em Saúde para Debate 2001; 25:91-107.

3. Costa EA. Vigilância sanitária: defesa e proteção da saúde. In: Rouquayrol MZ, Almeida Filho N, organizadores. Epidemiologia \& saúde. 5 a ed. Rio de Janeiro: Medsi; 1999. p. 327-351.

4. Brasil. Ministério da Administração e Reforma do Estado (Mare). Plano Diretor da Reforma do A pareIho do Estado. Brasília: Mare; 1995.

5. Barca DAV. A contratualização de desempenho institucional nas agências reguladoras do setor saúde: as experiências da Agência Nacional de Vigilância Sanitária (Anvisa) e da Agência Nacional de Saúde Suplementar (ANS) [monografia]. Brasília: Escola Nacional de Administração Pública; 2006.

6. Brasil. Lei no 9.782, de 26 de janeiro de 1999. Define - Sistema Nacional de Vigilância Sanitária, cria a Agência Nacional de Vigilância Sanitária e dá outras providências. Diário Oficial da União 1999; 27 jan.

7. Santos LA, Cardoso RLS. Avaliação de desempenho da ação governamental no Brasil: problemas e perspectivas. In: VI Congresso Internacional del CLAD sobre a Reforma del Estado y de la Administracion Pública. Anais... Buenos Aires: CLAD; 2001.

8. Di Pietro MSZ. Direito administrativo. 19a ed. São Paulo: Atlas; 2006.

9. Brasil. Ministério da Saúde. Agência Nacional de Vigilância Sanitária. Contrato de gestão que entre si celebram o Ministério da Saúde/M S e a Agência Nacional de Vigilância Sanitária/Anvisa. Diário O ficial da União 1999; 10 set.
10. Brasil. Ministério da Saúde. Agência Nacional de Vigilância Sanitária. Termos aditivos ao contrato de gestão que entre si celebram o M inistério da Saúde e a Agência Nacional de Vigilância Sanitária. Brasília: M inistério da Saúde; 1999. [acessado 2006 abr 12]. Disponível em: http://www.anvisa.gov.br/institucional/ anvisa/contrato/index.htm

11. Brasil. Ministério da Saúde. Agência Nacional de Vigilância Sanitária. Relatórios de execução do contrato de gestão. Brasília: Anvisa; 1999. [acessado 2006 maio 17]. Disponível em: http://www.anvisa. gov.br/ institucional/anvisa/contrato/index.htm.

12. Brasil. Portaria no 593, de 25 de agosto de 2000. Aprova o Regimento Interno e o Quadro Demonstrativo de Cargos em Comissão da Agência Nacional de Vigilância Sanitária. Diário Oficial da União 2000; 22 dez.

13. Brasil. Portaria Conjunta $n=174$, de 23 de fevereiro de 2000. Aprova sistemática de acompanhamento e avaliação do desempenho da ANVS. Diário Oficial da União 2000; 24 fev.

14. Brasil. Decreto no 4.726 , de 9 de junho de 2003. Aprova a estrutura regimental e quadro demonstrativo dos cargos em comissão e das funções gratificadas do Ministério da Saúde, e dá outras providências. Diário Oficial da União 2003; 10 jun.

15. Souto AC. Saúde e política: a vigilância sanitária no Brasil. São Paulo: Sobravime; 2004.

Artigo apresentado em 08/07/2008

Aprovado em 28/08/2009

Versão final apresentada em 05/10/2009 